\title{
Adaptive current protection in electrical complexes with small power plants
}

\author{
A.I. Smirnov ${ }^{1}$, J.E. Shklyarskiy ${ }^{2}$ \\ ${ }^{1}$ Department Of Information System And Computing Technologies, Saint Petersburg Mining \\ University, St. Petersburg, Russia \\ ${ }^{2}$ General Electric Department, Saint Petersburg Mining University, St. Petersburg, Russia
}

\begin{abstract}
The article considers electrical complexes with power plants of small capacity. The influence of power generation sources on short-circuit current distribution has been investigated. Reduced sensitivity of back-up current protection and dependence of current distribution on power plant capacity are revealed. Recommendations for minimizing false operation of short-circuit protection in networks with distributed power generation are proposed. An algorithm for adaptive current protection, which uses graph theory to determine the stages of selectivity of relay protection based on finding the shortest Dijkstra path and calculation of equivalent resistance in networks with multiple sources of power generation, which provides selectivity and sensitivity of current protection when changing the generated power of generators and the structure of the distribution network is presented. The algorithm uses communication lines with a central control unit to monitor the distribution network and update the current triggering of the relay protection in accordance with changes in the structure of the power grid. The proposed system is designed so that it can respond to dynamic changes in the structure of the network and the state of operation of power plants. Simulation modeling in the Matlab/Simulink software package was performed and the results of the algorithm are presented.
\end{abstract}

\section{Introduction}

Various types of small power generation sources, better known as distributed generation, are now connected to the distribution grid. According to the UES report, power generation from wind power plants increased 47.3 percent, and solar power plants increased 69.4 percent in 2019 [1]. The positive trend towards a further increase in renewable energy sources in the Russian energy system is supported by many objective prerequisites that have emerged at the current stage of energy development $[2,3,4]$ : the need to provide energy to remote areas; growing shortage of generating and network capacities amid high wear and tear of power system equipment; reduced efficiency of power system operation; limited investments allocated for the reconstruction of existing power facilities and the implementation of new construction. Under the existing conditions, the most promising scenario for the development of Russia's energy system is the transition to a combination of centralized and distributed power supply systems $[5,6]$. 
Conventional medium-voltage distribution networks $6-10 \mathrm{kV}$ typically have a radial single-ended feeder structure. Power system protection is a universal requirement for distribution networks, designed to detect faults and other abnormal operating conditions that could lead to loss of power supply and damage to equipment, which responds quickly (usually by opening circuit breakers to locate the fault) if such conditions are detected. When power system protection fails to operate, this can have serious consequences for the operation of electrical systems $[7,8]$.

\section{Problem statement}

The integration of distributed generation can negatively affect important functions of the distribution and transmission network, such as power flow [9], current protection levels, and faults [10], stability [11], network losses, power quality, etc. In addition to the abovementioned impacts, the introduction of distributed generation can jeopardize the proper operation of the short-circuit protection system. There are cases of non-triggering, false triggering of current protection, failure of coordination between relays and reclosing devices.

The modern concept of improvement of relay protection of electrical complexes and distribution networks, developed by scientific schools of Russia, is focused mainly on the development of simple and reliable current protections, as well as solving problems of detection of complex emergencies and protection of long-range redundancy [12-14]. The focus is on protection against single-phase earth faults [15], and the trend toward power generation close to the consumer, which requires consideration of a wider and more complex range of tasks, is practically ignored [16].

In the literature, there are various proposals for strategies and methods of adaptive current protection systems in conditions of the relative increase of distributed generation capacity in the power system. An adaptive protection scheme based on dividing existing distribution grids into zones and maintaining load balancing using the latest technologies to update power grid parameters was proposed in [17,18], which requires a large financial investment. Various authors, such as Baran [19], Mahat [20], Chen [21], and Yazdanpanahi [22] proposed methods for tuning the adaptive relay to maintain protection coordination. In [19], the authors proposed an adaptive scheme based on changing the setting of overcurrent protection operation by estimating the value of short-circuit current using an iterative method. In the paper [20], the authors proposed an adaptive selection of the appropriate operating characteristics of relays based on the methodology of assessing the state of detected faulty sections, as well as determining the magnitude of short-circuit current when connected to the network and in stand-alone mode. The authors of [22-23] proposed adaptive protection strategies based on controlling the output current in distributed generation sources connected to the grid using an inverter to reduce the generator contribution to the short-circuit current thereby ensuring the correct operation of the overcurrent protection with preset relay settings. However, when the network topology changes, the preset relay parameters must be adaptive for the proposed strategy to be effective.

\section{Research methodology}

Assessment of the impact of distributed generation on the current protections of power grids is the first step in developing algorithms for adaptive protection, which allows us to fill gaps in this area and expand the existing concept of protection of electrical complexes and power grids (Concept of development of relay protection and automation of electric grid 
complex to PAO ROSSETI's 2015), focusing on the communication approach as the most reliable. These methods should form the basis for developing fast, selective, and reliable protection schemes that can solve the aforementioned problems in the presence of distributed power generation sources on the grid.

The applied types of relay protection in distribution networks are analyzed: differential protection will not work adequately if an additional power supply appears in the protected zone; distance protection is negatively affected by transient processes that are inevitable in distributed generation; protection relays based on voltage monitoring have reduced sensitivity when working together with the power system. Therefore, the overcurrent protection is chosen to implement adaptability. This provides primary and backup relay protection, applies to all network topologies, depends on one parameter and has a simple way of calculating the pickup setpoint.

A number of restrictions and assumptions were made in the research: three-phase short current is considered; interphase capacitances are not considered; line length 50км, studies have also been conducted for shorter lengths; the generator's own protection is not considered; the considered range of rated power of distributed generation is 1-9 MW.

\subsection{Decreased sensitivity of protection}

A typical fragment of a grid section with a power plant connected to substation $B-2$ is shown in Figure 1a.

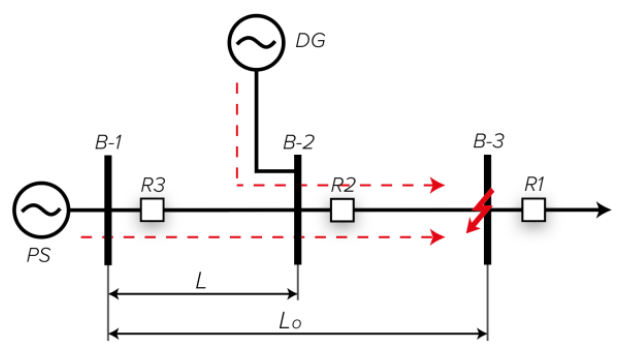

a)

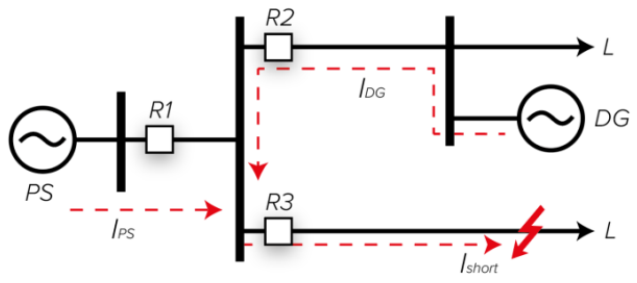

b)

Fig. 1. General view of distributed generation wiring diagram: a) reduced sensitivity of current protection; b) false tripping of current protection.

To analyze the influence of the distributed generation source on the magnitude of the fault current in the feed. er, a common feeder from substation $B-1$ to $B-3$ is taken to calculate the base value, where the distributed generation source is located at distance $L$ and a threephase short-circuit is simulated near substation $B-3$. After the transformations presented in (Smirnov 2020), the three-phase short-circuit current is defined by equation (1)

$$
I_{\text {short }}=\frac{U_{0} \cdot\left(Z_{p s}+D Z_{\text {line }}+Z_{d g}\right)}{\sqrt{3}\left(D Z_{\text {line }}\left(Z_{\text {line }}-Z_{p s}\right)-D^{2} Z_{\text {line }}^{2}+\left(Z_{\text {line }} Z_{p s}+Z_{p s} Z_{d g}+Z_{d g} Z_{\text {line }}\right)\right)} \text {, }
$$

where $D$ is the parameter of the generator removal relative to the total feeder length $L o$ from the substation $B-1 ; U O$ is the reduced system voltage; $Z$ is the total impedance of the central power system, line, and power plant. Equation (2) describes the contribution of the central power system (Figure 1a) to the total short-circuit current. 


$$
\left.\left.I_{\text {short_R3 }}=\frac{U_{0} Z_{d g}}{\sqrt{3}\left(D Z_{\text {line }}\left(Z_{\text {line }}-Z_{p s}\right)-D^{2} Z_{\text {line }}^{2}+\left(Z_{\text {line }} Z_{p s}+Z_{p s} Z_{d g}+Z_{d g} Z_{\text {line }}\right)\right.}\right)\right),
$$

(2)

The contribution of the central power system to the short-circuit current will be determined by the total resistance of the feeder, the local short-circuit capacity, the capacity of the local power source, and its location.

The effect of distributed generation on short-circuit currents depends on the type of generator and how it is connected to the power grid (directly or initially converted using an inverter $[24,25]$. In the case of rotating generators directly connected to the grid (3), the generator impedance $Z_{d g}=R+j X$ in short-circuit mode can be determined as follows [26,27]:

- For synchronous generators, active resistance will be $\mathrm{R}=0.15 \mathrm{X}$.

- For asynchronous generators, $\mathrm{R}=0.1 \mathrm{X}$.

$$
X=\frac{x_{d}^{\prime \prime}}{100} \cdot \frac{U_{n}^{2}}{S_{n}}
$$

where $x_{d}$ " is the sub transient reactance; $U_{n}$ is the rated output voltage; $S_{n}$ is the generator rated full power. It should be noted that it is necessary to consider the connection point of the power generators in power plants designing in order to minimize the influence of distributed generation on relay protection. Also, the internal resistance of distributed generation units changes because this is a complex of many generating devices connected to one bus, which can turn off due to breakdown or lack of consumption, as well as generate varying power due to climatic conditions, etc.

\subsection{False tripping of the protection}

False tripping of the protection, which disconnects the serviceable feeder, occurs due to the contribution of the distributed generation to the short-circuit current in the adjacent feeder connected to the same substation (Figure 1b). In this case, the short-circuit current contribution of the distributed generation unit is directed against the power flow to the short-circuit point. The contribution of the distributed generation to the short-circuit current can exceed the overcurrent relay trip current and cause the faulty feeder to trip before the actual shortcircuit is cleared. This phenomenon is known as false or sympathetic tripping of the protection and belongs to the category of problems that selective protections have. To investigate false tripping of the protection, another feeder is added to the developed simulation model in which a short circuit occurs, Figure $1 \mathrm{~b}$. The short-circuit location of the added feeder iteratively varies in the range from 1 to $50 \mathrm{~km}$ in $5 \mathrm{~km}$ steps. For each iteration, the relative position of the generator block in the feeder is reduced by $5 \mathrm{~km}$ from half the full length of the identical feeder. The feeder short-circuit contribution is recorded for four different distributed generation capacities of $1,3,6$, and $9 \mathrm{MW}$.

\subsection{Algorithm for determining the structure of the distribution network}

Selectivity is an essential requirement in protection systems to isolate the faulty section with the nearest circuit breaker so that the other sections of the distribution network continue to operate. Figure $2 \mathrm{a}$ shows a general diagram of a distribution network with power plants and loads that are connected to different bus bars. Through the combination of circuit breakers $R 5$ and $R 6$, various alternative distribution network structures can be 
formed. Figure $2 \mathrm{~b}$ shows a similar distribution network structure in the form of a graph, where the vertices are the circuit breakers, power plants, and loads, and the power lines are the edges of the graph.

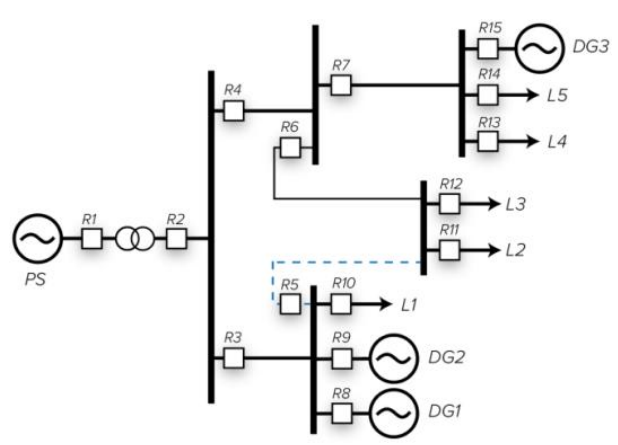

a)

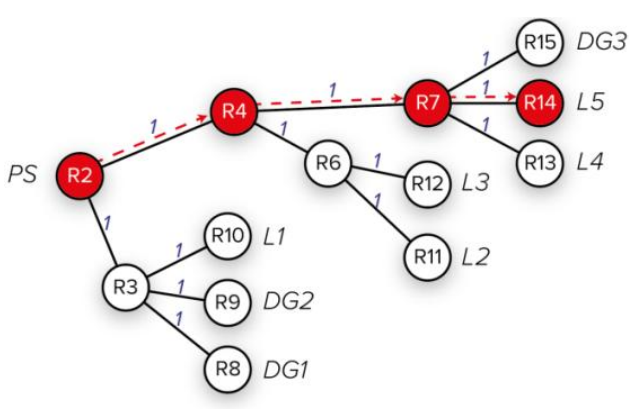

b)

Fig. 2. Schematic diagram of the investigated power network: a) Structure of the distribution network; b) Distribution network graph.

For the relay hierarchy to be dynamic and updated, an algorithm should be used that defines the structure of the distribution network whenever the states of the breakers affecting it change. Once the structure of the distribution network and its relay hierarchy have been defined, it is not difficult to determine suitable time delays.

For automatic determination of the hierarchy, it is proposed to use the Dijkstra algorithm, which determines the shortest path between two vertices. Power sources are taken as initial vertices, and loads are taken as final vertices. A detailed description of the algorithm is presented in the article [28]. It should be noted that the proposed method can also be used for power flow planning, load sharing, and generation.

\subsection{Algorithm for determining the mutual resistance}

To calculate short-circuit currents in power grids with distributed energy sources under conditions of changing power grid topology, it is necessary to use basic techniques of equivalent transformations known from the theory of linear circuits [29]. The main purpose of the equivalent transformations is to determine the mutual resistances between the power sources and the short-circuit location.

The algorithm developed [29] presents the distribution network in the form of a graph, taking as edges the elements whose resistance must be taken into account when calculating the equivalent resistance, and as vertices - the points of their connection. This allows taking into account the different resistances of overhead lines and cable lines in all parts of the distribution network.

The main advantage of the developed algorithm is the possibility of a different interpretation of the data array for different calculation conditions, for example, it is possible to specify forward, reverse, and zero sequence resistances as an array assignment or to calculate separately the active and inductive components of impedance. Since the algorithm is designed similarly to the previous algorithm based on graph theory, it can use a similar array assignment of the network structure and calculate short-circuit currents. 


\subsection{Adaptive current protection algorithm}

In the developed system of adaptive protection, the short-circuit current passing through the relay (4) takes into account the current from each source and the influence coefficients of the distributed generation and is calculated based on the current superposition method:

$$
I_{r}=\sum_{i=1}^{m} P P_{d g(i)} \cdot k_{r(i)} \cdot I_{\text {shart-dg(i) }}+I_{\text {short_ps }} \cdot P P_{p s}
$$

where $m$ is the total number of distributed generation sources; $P P$ is the state of the power system and generators (on or off); $I_{\text {short_dg }}$ is the contribution to the short-circuit current from a distributed generation source. $k_{(i) r}$ is the contributing factor to the shortcircuit current from each source.

The contribution coefficient of the source of distributed generation can be expressed as the ratio of short-circuit current from the power system without distributed generation to the short-circuit current with distributed generation, where the short-circuit currents are determined using the developed algorithm [30].

The developed algorithms make it possible to accurately determine the distribution network structure and set two key settings for protective devices, which are crucial for the safe and reliable operation of the electrical complex, namely the overcurrent protection relay triggering current value and the tripping delay time to ensure proper selectivity. The developed algorithms can be combined and implemented in the central controller of the distribution network automation system.

\section{Simulation results}

\subsection{Decreased sensitivity of protection}

To investigate the sensitivity reduction of current protection, a simulation model similar to Figure 1a in the Matlab/Simulink software environment is developed. A induction generator is connected to the main feeder in substation $B-2$. The cable line was modeled as conventional aluminum cable conductors with a cross-section of $240 \mathrm{~mm}^{2}$. Then the connection point of the power plant was changed in relation to the total feeder length of $50 \mathrm{~km}$, to determine the point at which there is a maximum reduction in the sensitivity of the current protection [31]. The influence of the power plant capacity on the contribution to the shortcircuit current from the central power system was determined figure 3. In the test model, the parameters of cable lines are set so that the influence of distributed generation on the short-circuit current was maximum and simulation was performed with increasing power plant capacity in increments of $1 \mathrm{MW}$. 


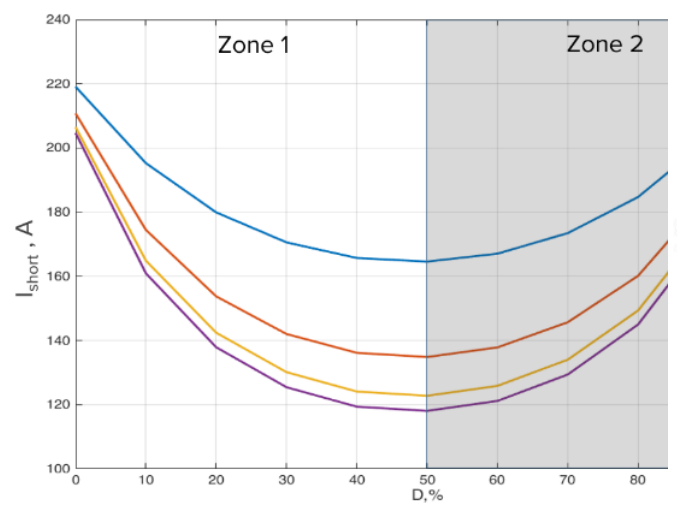

a)

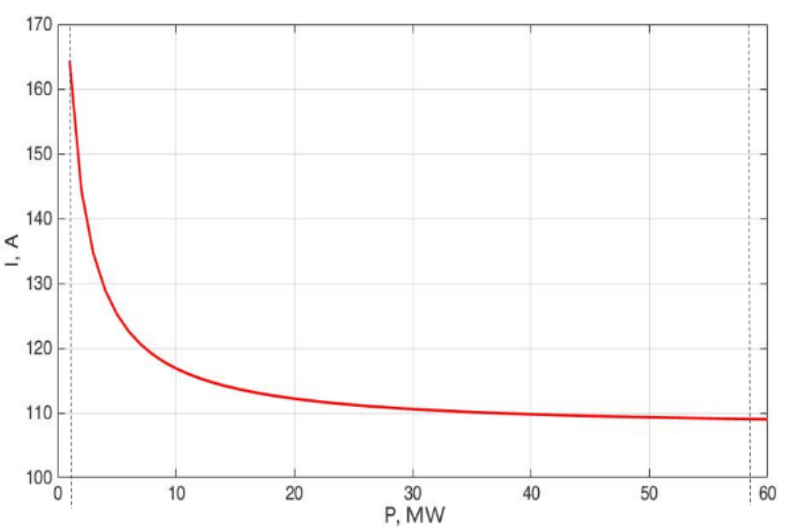

b)

Fig. 3. a) Dependence of the contribution to the short-circuit current from the power system on the connection point of the DG; b) Dependence of the measured current of relay R3 (Fig.1a) on the power plant power during short-circuit.

The simulation results, shown in Figure 3b, show that the change in short-circuit current depending on the capacity of the local power plant at constant system parameters has a hyperbolic character. It is important to note that the greatest influence on the distribution of currents in the studied network has a change in generation capacity in the range up to 10 MW. In this range, it is necessary to monitor the change in power of distributed generation, to ensure the correct operation of current protection.

The sensitivity coefficient for different power of the main (Table 2) and standby protection (Table 1) was calculated numerically. According to Table 1, there is a significant decrease in the coefficient of sensitivity of the standby protection when changing power and an increase for the main protection.

Table 1. Standby current protection sensitivity coefficient

\begin{tabular}{cccccc}
\hline line length, km & $\mathrm{P}=0 \mathrm{MW}$ & $\begin{array}{c}\mathrm{P}=1 \mathrm{MW} \\
\mathrm{T}\end{array}$ & $\mathrm{P}=3 \mathrm{MW}$ & $\begin{array}{c}\mathrm{P}=6 \\
\mathrm{MW}\end{array}$ & $\begin{array}{c}\mathrm{P}=9 \\
\mathrm{MW}\end{array}$ \\
\hline $\mathbf{5 0}$ & 1,280 & 0,425 & 0,345 & 0,252 & 0,214 \\
$\mathbf{4 0}$ & 1,617 & 0,610 & 0,394 & 0,307 & 0,280 \\
$\mathbf{3 0}$ & 1,987 & 1,005 & 0,655 & 0,535 & 0,495 \\
$\mathbf{2 0}$ & 2,248 & 1,414 & 0,986 & 0,752 & 0,620 \\
$\mathbf{1 0}$ & 2,683 & 1,790 & 1,376 & 1,012 & 0,868 \\
$\mathbf{5}$ & 3,138 & 2,138 & 1,748 & 1,335 & 1,030 \\
\hline
\end{tabular}

Table 2. Main current protection sensitivity coefficient

\begin{tabular}{cccccc}
\hline line length, km & $\mathrm{P}=0 \mathrm{MW}$ & $\mathrm{P}=1 \mathrm{MW}$ & $\mathrm{P}=3 \mathrm{MW}$ & $\begin{array}{c}\mathrm{P}=6 \\
\mathrm{MW}\end{array}$ & $\begin{array}{c}\mathrm{P}=9 \\
\mathrm{MW}\end{array}$ \\
\hline $\mathbf{5 0}$ & 1,508 & 1,895 & 2,109 & 2,196 & 2,230 \\
$\mathbf{4 0}$ & 1,789 & 2,109 & 2,357 & 2,462 & 2,523 \\
$\mathbf{3 0}$ & 1,906 & 2,265 & 2,559 & 2,687 & 2,739 \\
$\mathbf{2 0}$ & 2,173 & 2,493 & 2,679 & 2,807 & 2,895 \\
$\mathbf{1 0}$ & 2,392 & 2,702 & 2,953 & 3,089 & 3,179 \\
$\mathbf{5}$ & 2,702 & 3,019 & 3,221 & 3,376 & 3,436 \\
\hline
\end{tabular}


As a result of the simulation, the obtained values of sensitivity coefficients correspond to the minimum requirements for the main current protection $k_{f} \geq 1.5$. At the same time, with the increase of power of distributed generation, the sensitivity of the main current protection increases significantly. When connecting distributed generation and increasing its power, a similar dependence of the change in the sensitivity factor for different line lengths is observed.

For the standby current protection, the sensitivity coefficient initially corresponds to the minimum requirements for the standby protection $k_{f} \geq 1,2$. However, for the simulation, we registered a decrease in the sensitivity factor of the standby current protection when changing the power of distribution from $1 \mathrm{MW}$ to $3 \mathrm{MW}$ by $43 \%$ for a total length of the line of $50 \mathrm{~km}$, when changing the power from $3 \mathrm{MW}$ to $6 \mathrm{MW}$, the sensitivity of the standby current protection decreased additional by $27 \%$. When reducing the total length of the feeder, the decrease in sensitivity between the ranges of power changes has approximately the same dependence.

\subsection{False tripping of the protection}

Figure $4 \mathrm{a}$ and figure $4 \mathrm{~b}$ show the results of the short-circuit current variation in the serviceable feeder depending on the distance of the distributed generation and the short-circuit location in the damaged feeder. In accordance with the calculation of the magnitude of the current of operation of protection in the direction of power for the serviceable feeder, the surface of the graph is divided into a zone of false operation of current protection (blue) and the zone of no operation of current protection.

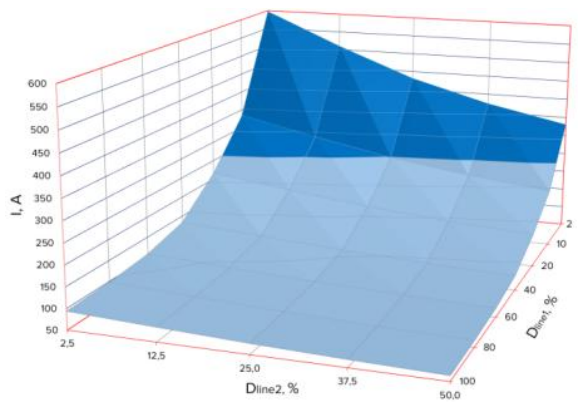

a)

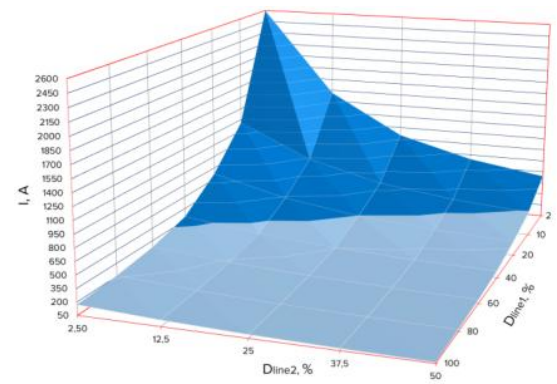

b)

Fig. 4. False tripping of current protection at distributed generation capacity:

a) $1 \mathrm{MW}$; b) $9 \mathrm{MW}$.

At the power of a distributed generation of $1 \mathrm{MW}$, false tripping of the protection occurs when short-circuiting occurs at the beginning of the damaged feeder, and the value of shortcircuit current significantly exceeds the current cutoff of relay protection, which operates without time delay, which prevents the occurrence of false operation, provided time delay in the reverse direction of current protection of the serviceable feeder.

False tripping of the protection at the power of a distributed generation of 6 and $9 \mathrm{MW}$ similar to the power of $3 \mathrm{MW}$ and occurs at short-circuiting in the zone up to $10 \%$, but when the distributed generation is removed to $12.5 \%$ from the beginning of the line, the short-circuit zone increases to $60 \%$, at which the dependent characteristic of the maximum current protection will have some time delay and a false operation in the intact feeder will occur.

Thus, the simulation results show that the most serious influence of the distributed generation on false alarms occurs when its distance from the common busbar is less than $10 \%$ of the common line, provided that the lines have the same characteristics. Besides, it can be 
concluded that such a situation is most likely when the short-circuit location is near the substation. Based on the simulation results, to minimize false trippings, it is necessary to make the matching of the time delay of operation of protection with parallel sections in the reverse direction of the power flow; it is necessary to ensure an even distribution of the load between the feeders to balance the power flows before the short circuit; the location of distributed generation from a common substation with a parallel feeder should be more than $50 \%$, subject to the same parameters of the lines, Zone 2 on Figure $3 \mathrm{a}$. It allows to control the decrease in sensitivity and reducing the likelihood of false tripping.

\subsection{Adaptive current protection}

In the simulated distribution network shown in Figure 5, short-circuit currents can flow in both directions and the necessary condition for selective protection is to determine the power flow. Besides, a periodic interrogation of all devices is necessary to detect changes in their state in advance.

Particular attention is paid to circuit breakers Relay_l and Relay_2, as these circuit breakers determine whether the distribution network operates autonomously or in parallel with the central power system and whether the current protection selectivity stages need to be redistributed.

The operation of the proposed protection scheme is tested on the simulated distribution network, shown in Fig. 6, which operates according to a predetermined scenario. The simulated distribution network simulation includes a diesel and a wind turbine generator, which is connected to a $6 \mathrm{kV}$ grid with an isolated neutral point through a step-up transformer and a solar power plant connected through a frequency converter (Vasilev and Tung 2019). Distributed generation sources operate with load shedding control and shut down when power consumption decreases significantly.

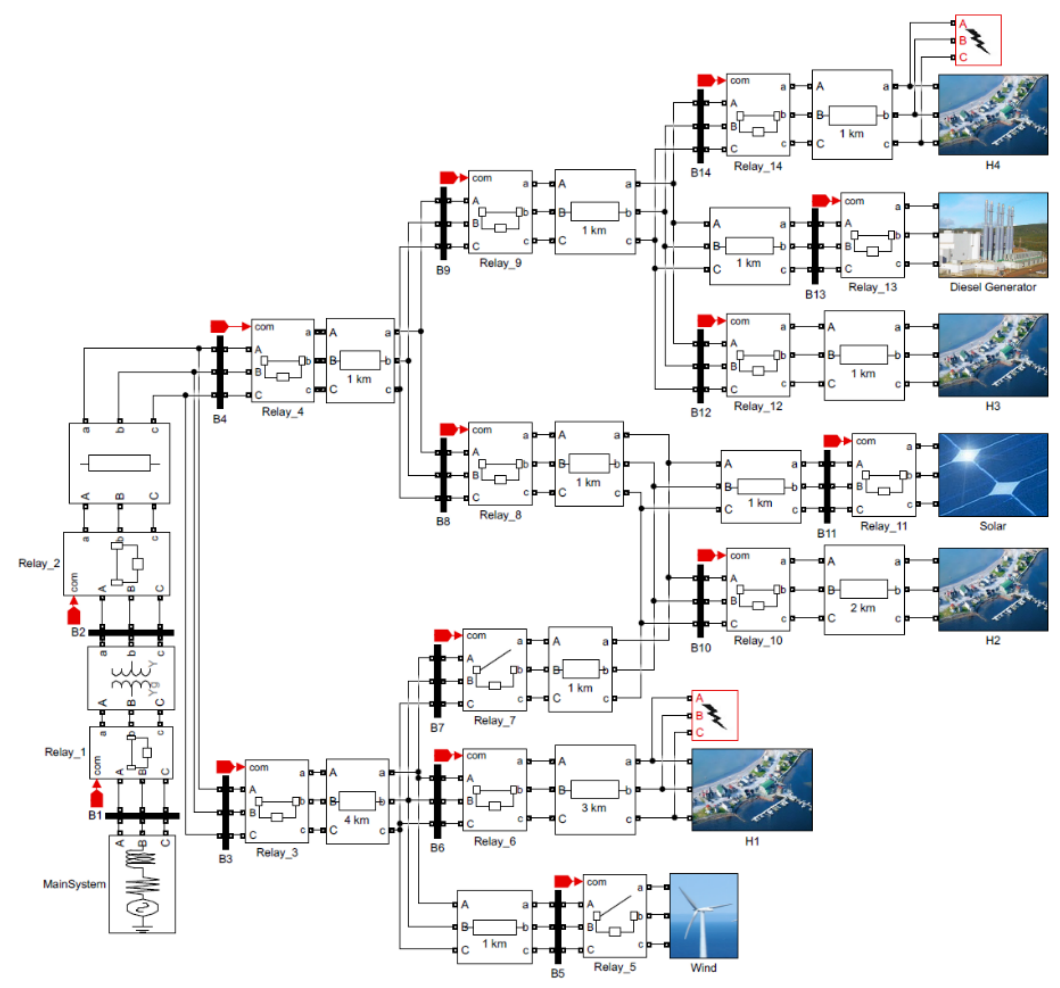


Fig. 5. Power grid simulation model with multiple DG sources in Matlab/Simulink.

The electrical resistance of the simulated line $R=0.051 \mathrm{Ohm} / \mathrm{km}$ and inductive resistance $L=0.083 \mathrm{Ohm} / \mathrm{km}$ is selected for all sections of the simulation model, which correspond to a single-core copper cable with a cross-section of $500 \mathrm{~mm} 2$ and a continuous allowable current load 1025A; Loads H1 = 7,3 MVA, H2 = 3,7 MVA, H3 = 2,2 MVA, H4 = 1,7 MVA; generator parameters: wind $=6 \mathrm{MW}$, solar $=2.5 \mathrm{MW}$ and Diesel Generator $=4 \mathrm{MW}$.

A specially defined scenario is used to demonstrate various aspects of current protection:

1. The distribution grid starts operating at full load, all sources are switched on, and the grid operates in connection with the central power grid.

2. At $\mathrm{t}=0.2 \mathrm{~s}$, a three-phase short circuit occurs at load $\mathrm{H} 1$ and the current protection Relay_6 is triggered and disconnects the load. Because of the lower power consumption in the system, the wind turbine is switched off.

3. At $\mathrm{t}=0.5 \mathrm{~s}$, the central power system is shut down due to maintenance, and the distribution network operates in stand-alone mode.

4. At $\mathrm{t}=0.65 \mathrm{~s}$, when the network is operating in stand-alone mode, a short-circuit occurs at the load $\mathrm{H} 4$ and the Relay_ 14 protection is triggered.

5. At $\mathrm{t}=0.9$, the parallel operation with the central power system is restored.

6. At $\mathrm{t}=1 \mathrm{~s}$, the short circuits at loads $H I$ and $H 4$ are eliminated and due to the increased power consumption in the network, the wind turbine starts operating.

The developed model can take different structures depending on the state of Relay_7 and Relay_8. In the simulated operation scenario, Relay_7 is open and loads $\mathrm{H} 2$ are connected to the upstream network via Relay_8. Therefore, the distribution network has two parallel branches in its structure. The results of the current changes are shown in Figure 7.

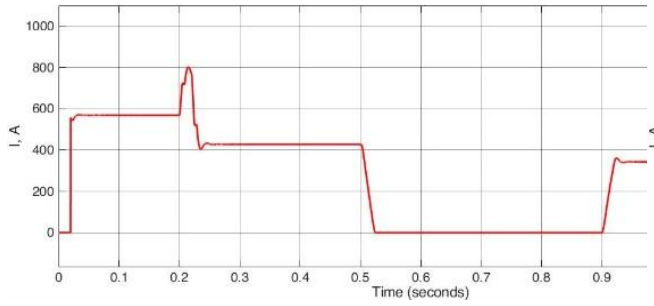

a)

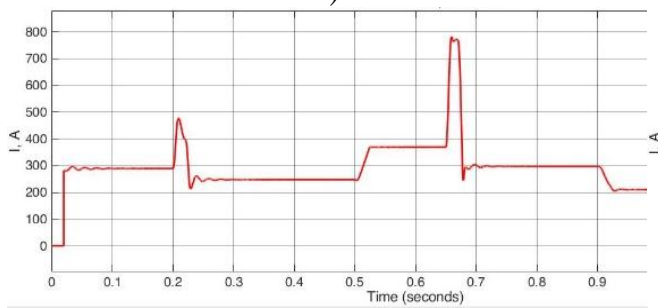

c)

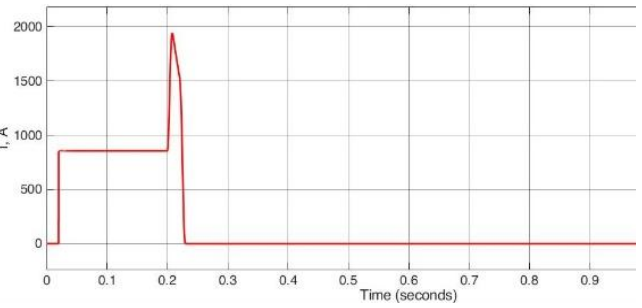

b)

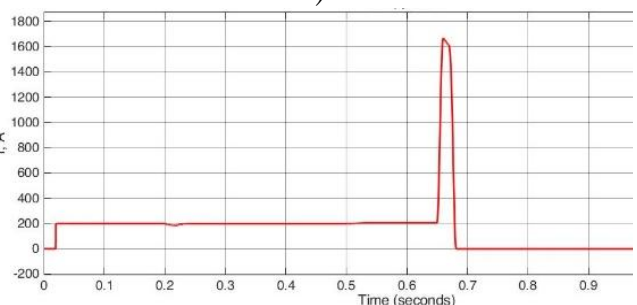

d) 


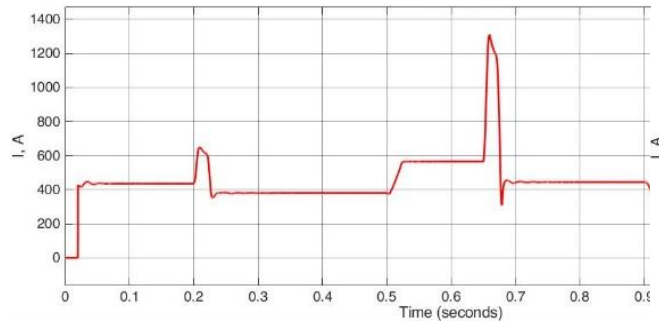

e)

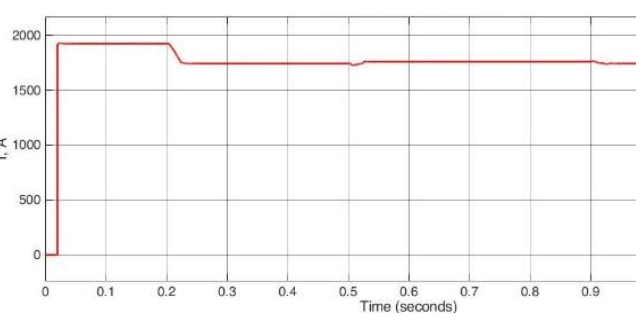

f)

Fig. 6. Results of current measurements during a given scenario: a) Central power system; b) Solar power plant; c) Diesel generator; d) Relay_6 short-circuit trip on load H1; e) Relay_14 short-circuit trip on load H4; f) Relay 6 and Relay 14 operating current.

The obtained graphs of the distributed generation sources show the change in the currents flowing in different parts of the power grid when changing the mode of operation, which directly affects the sensitivity of the current protection. Ensuring the short-circuit currents trip due to the developed algorithms of adaptive current protection when changing the generated power is shown in Figure $6 \mathrm{~b}$ and Figure $6 \mathrm{~d}$.

The operation current of the overcurrent protection in Figure $7 \mathrm{e}$ at short-circuiting at loads $H 1$ and $H 4$ are approximately the same due to the small difference in the line parameters, and hence the mutual impedance. Nevertheless, a noticeable $0.2 \mathrm{~s}$ decrease in tripping current can be seen as a result of wind generator tripping, which would reduce the sensitivity of the current protection by about $18 \%$ for the simulation model under study. Adaptive modification of the protection triggering current allowed to take into account the decrease in sensitivity and to ensure correct operation.

\section{Conclusion}

Based on the study of the impact of distributed generation sources on the current protection of power grids, the following results were achieved:

1. The dependence of the contribution to the short-circuit current on the change in the power of distributed generation arising due to the dynamic mode of operation of renewable energy sources is obtained. Based on modeling it is proved that the sensitivity of the current protection of the long-range redundancy can decrease up to $70 \%$.

2. Conditions of false alarms and recommendations to minimize their occurrence are defined.

Algorithms have been developed that determine the network structure, calculate and assign the parameters of directional current protection before an emergency occurs. The developed adaptive current protection system can monitor the dynamic changes occurring in the distribution network, adapt to the addition of new devices and adjust the necessary settings.

\section{References}

1. Report on the Functioning of UES of Russia in 2019. (Moscow: OAO «SO UES», 2019).

2. A.F. D'yakov Priorities Are Set, Elektroenergia. Transmission and Distribution, 1, 1622 (2010).

3. E. Mirolyubova Tendencies of the Generating Sector of Power Engineering, Elektroenergiya. Transmission and Distribution, 2(12), 12-14 (2010). 
4. E. Iakovleva, D. Guerra, A. Shklyarskiy Alternative Measures to Reduce Carbon Dioxide Emissions in the Republic of Cuba, Journal of Ecological Engineering, 21 (4), 55-60 (2020).

5. E.M. Perminov Renewable Energy Is Inexhaustible and Necessary, Unified Grid Energy, 3, 56-63 (2010).

6. O. Novosyolova Small-Scale Generation - the Way to „Intellectual“ Power Systems, 5, 20-21 (2011).

7. S. Boljevic, M. Conlon Fault Current Level Issues for Urban Distribution Network with High Penetration of Distributed Generation, In 2009 6th International Conference on the European Energy Market, 1-6 (2009).

8. Y.L Zhukovskiy, V.V. Starshaia, D.E. Batueva, A.D. Buldysko Analysis of technological changes in integrated intelligent power supply systems, 249-258 (2018).

9. G. Papaefthymiou, P. H. Schavemaker, L. van der Sluis, W. L. Kling, D. Kurowicka, R. M. Cooke Integration of Stochastic Generation in Power Systems, International Journal of Electrical Power \& Energy Systems, Selection of Papers from 15th Power Systems Computation Conference, 28 (9), 655-67 (2005).

10. M. Reza Stability analysis of transmission systems with high penetration of distributed generation. (Technische Universiteit Delft 2006).

11. P. Vermeyen Effect of Distributed Generation on Fault Detection and Ripple Control. (Effect van Gedistribueerde Opwekking Op Foutdetectie En Centrale Afstandsbediening 2008).

12. Yu. Lyamets, G. Nudelman, A. Pavlov, E. Efimov, J. Zakshek Recognizability of power transmission faults. P. 1. Recognizability of the damage place, Elektrichestvo, 2, 1623 (2001).

13. V. Nagai, I. Nagai, V. Nagai Adaptive Measuring Bodies of Emergency Components of Reserve Protections of Electric Distribution Networks, In Modern Directions of Development of Relay Protection and Automatics Systems of Power Systems, 134-40 (2009).

14. V.I. Nagai Long-Distance Backup Protections of Intermediate Substations of Radial Overhead Lines, Elektrichestvo, 4, 2-7 (2002).

15. Shuin, V.A., и V.A Gusenkov. 2001. «Protection against the earth faults in the $6-10 \mathrm{kV}$ networks». NTF «Energopress», Energetik, 104.

16. Y. Zhukovskiy, D. Batueva, A. Buldysko, M. Shabalov Motivation towards energy saving by means of IoT personal energy manager platform, IOP Publishing, 1333, 062033 (2019).

17. S.M. Brahma, A.A. Girgis Development of adaptive protection scheme for distribution systems with high penetration of distributed generation, IEEE Transactions on Power Delivery, 19 (1), 56-63 (2004).

18. S.A.M. Javadian, M.-R. Haghifam Implementation of a New Protection Scheme on a Real Distribution System in Presence of DG, In 2008 Joint International Conference on Power System Technology and IEEE Power India Conference, 1-7 (2008).

19. Mahat, Pukar, Z. Chen, B. Bak-Jensen, C. Leth Bak A Simple Adaptive Overcurrent Protection of Distribution Systems With Distributed Generation, IEEE Transactions on Smart Grid, 2 (3), 428-37 (2011).

20. Baran, Mesut, I. El-Markabi Adaptive over Current Protection for Distribution Feeders with Distributed Generators, In IEEE PES Power Systems Conference and Exposition, 1399-1403 (2004). 
21. S. Hsieh, C. Chen, C. Tsai, C. Hsu, C. Lin Adaptive Relay Setting for Distribution Systems Considering Operation Scenarios of Wind Generators, IEEE Transactions on Industry Applications, 50 (2), 1356-63 (2014).

22. Yazdanpanahi, Hesam, Y. W. Li, W. Xu A New Control Strategy to Mitigate the Impact of Inverter-Based DGs on Protection System, IEEE Transactions on Smart Grid, 3 (3), 1427-36 (2012).

23. Su, Chi, Z. Liu, Z. Chen, Y. Hu An adaptive control strategy of converter based DG to maintain protection coordination in distribution system, B IEEE PES Innovative Smart Grid Technologies, Europe, 1-6 (2014).

24. B. Yu. Vasiliev, A. E. Kozyaruk, D. V. Mardashov Increasing the Utilization Factor of an Autonomous Inverter under Space Vector Control, Russian Electrical Engineering 91 (4), 247-54 (2020).

25. M. J. Carrizosa, N. Stankovic, J. Vannier, Y. E. Shklyarskiy, A. I. Bardanov MultiTerminal Dc Grid Overall Control with Modular Multilevel Converters, Journal of Mining Institute, 243, 357-357 (2020).

26. A. I. Smirnov, I. N. Voytyuk Diagnostics of Inter-Turn Short-Circuit in the Stator Winding of the Induction Motor, IOP Conference Series: Materials Science and Engineering, 643 (1), 012023 (2019).

27. A.I. Voldek Electrical Engineering, Electrotechnics and Electrotechnologies and Electric Power Engineering. (Publishing house «Peter» 2008).

28. A.I. Smirnov, J.E. Shklarsky Structure of Current Protection of a Distribution Network Based on the Shortest Path Search Algorithm, Proceedings of Tula State University. Tekhnicheskie Nauki, 5, (2020). https://elibrary.ru/item.asp?id=42983111.

29. D.A. Ulakhovich Fundamentals of the Theory of Linear Electric Circuits. (BXVPeterburg 2009).

30. D. Ivanchenko, A. Smirnov Identification of Interturn Faults in Power Transformers by Means of Generalized Symmetrical Components Analysis, E3S Web of Conferences, 140, 04007 (2019).

31. A.I. Smirnov Influence of the Distributed Generation on the Current Protection Sensitivity, Proceedings of Tula State University. Technical Sciences, 6, (2020). 